\title{
HEIGHTENING LEVELS OF COMPASSION TOWARDS SELF AND OTHERS THROUGH USE OF COMPASSIONATE MIND TRAINING
}

\author{
Elaine Beaumont MSc BSc ${ }^{1}$
}

Caroline J. Hollins Martin PhD MPhil BSc²

\begin{abstract}
${ }^{1}$ Cognitive Behavioural Psychotherapist, EMDR Europe Approved Practitioner and Lecturer in Counselling and Psychotherapy, School of Nursing, Midwifery, Social Work \& Social Sciences, University of Salford, Frederick Road, Salford, Greater Manchester, UK, M6 6PU. E-mail: E.A.Beaumont@salford.ac.uk

2Professor in Maternal Health, School of Nursing, Midwifery and Social Work, Edinburgh Napier University, EH11 4BN. Email: C.HollinsMartin@napier.ac.uk
\end{abstract}

\section{Corresponding author}

Elaine Beaumont, School of Nursing, Midwifery, Social Work \& Social Sciences. Mary Seacole (Room MS3.17), University of Salford, Frederick Road, Salford, Greater Manchester, UK, M6 6PU. Tel: 00441612952388 E-mail:

E.A.Beaumont@salford.ac.uk

Word Count 6012 with references and 4787 without references 


\begin{abstract}
Background: Continued absence of strategies that promote self-care puts midwives at risk of experiencing symptoms of stress, empathic distress fatigue, burnout, and compassion fatigue, which can all impact on the performance of midwives and the level of compassion they show to others. Objective: The objective of this paper is to outline a possible education strategy for student midwives that has the potential to impact upon the level of compassion that the individual can show both to themselves and others in times of suffering. Suggested Approach: Compassionate Mind Training (CMT) has been found to be beneficial in clinical populations with individuals who report symptoms of primary trauma, low levels of self-compassion, and who are selfcritical. Student midwives bear witness to the traumas of others, which makes considering an intervention to help student midwives who may experience symptoms of secondary trauma, self-criticism, or low levels of self-compassion whilst in training important. Conclusion: Incorporating CMT into undergraduate midwifery degree programmes may help student midwives become sensitive to their own suffering, and could potentially help them cope with emotional demands, placement anxieties and organisational pressures.
\end{abstract}




\section{INTRODUCTION}

Sustaining compassion across long periods of time is an essential part of a midwife's role, with stress experienced from continual exposure to traumatic events potentially resulting in emotional fallout. As a consequence, midwives may experience symptoms of empathic distress fatigue (Klimecki \& Singer, 2012), compassion fatigue (Beaumont et al, 2015; Sabo, 2006), secondary trauma (Leinweber \& Rowe, 2010), and burnout, which have the potential to impact upon the level of compassion the individual is able to show towards self and others (Figley, 1995, 2002). Introducing student midwives to interventions which aim to promote self-compassion is therefore vital, because it may furnish them with some of the coping strategies needed to manage emotional distress. The aim of this paper is to explore an intervention designed to increase student midwives levels of compassion for self and reduce levels of self-criticism.

Empathic distress fatigue is the consequence of emotional, psychological, physical, spiritual, and occupational exhaustion, and according to Klimecki and Singer (2012) it is the cause of burnout and compassion fatigue. Compassion fatigue was a term first coined by Joinson (1992) and is a form of burnout which can impact negatively on healthcare professionals who bear witness to suffering. Klimecki and Singer (2012) suggest that compassion fatigue is a result of placing the needs of other people above one's own and can lead to emotional, physical, and psychological damage. According to Klimecki and Singer, compassion fatigue may be prevented by using exercises that activate the neural pathways associated with compassion, empathic concern, positive feelings, and altruistic behaviour.

Richards (2013) argues that healthcare professions should expect clinicians to nurture their own well-being. Therefore, examining interventions that aim to 
promote self-care and cultivate self-compassion warrants consideration. Gilbert (2005, p. 217) defines compassion as a quality that "aims to nurture, look after, teach, guide, mentor, soothe, protect, offer feelings of acceptance and belonging". These factors are important because work related stress has been shown to impact on healthcare practitioner's concentration levels and ability to communicate effectively (Raab, 2014). This paper intends to explore an intervention which could potentially equip midwifery students with the psychological tools needed to cope with organisational, personal, academic, and placement demands. Compassionate Mind Training (CMT) may enhance levels of compassion, reduce self-criticism, and help prepare student midwives to face the challenges of academic and organisational pressures, traumatic childbirth (Leinweber \& Rowe, 2010; Mollart, 2013; Sheen et al., 2014), and stillbirth (Hollins Martin \& Forrest, 2013; Hollins Martin et al., 2013, 2014).

A literature review was conducted to examine what research has already addressed in relation to self-compassion, compassion for others, empathic distress fatigue, compassion fatigue, and burnout within the healthcare professions. From the body of literature it was identified that patient dissatisfaction (Vahey et al., 2004), insufficient training, shortage of personnel and lack of support from colleagues are all linked to staff burnout (Shanafelt et al., 2002). Continued absence of self-care strategies can put midwives at risk of burnout (Miller, et al., 2002) and compassion fatigue (Figley, 2002), and can also create a tendency to be more self-judgemental (Beaumont et al., 2016). van Mol et al. (2015) conducted a systematic review to examine the literature connected to emotional suffering amongst healthcare practitioners. The authors concluded that the true scale of emotional distress among healthcare practitioners was uncertain with prevalence rates ranging from $7.3 \%-40 \%$ 
for compassion fatigue, and $0-70 \%$ for burnout. In response van Mol et al. (2015) suggesst that policy makers introduce practitioners to interventions that help prevent the negative consequences of emotional distress. This sentiment is echoed by Raab (2014), who conducted a review of literature which concluded that further research focusing on cultivating self-compassion among healthcare practitioners is warranted. Hence, enhancing levels of self-compassion may have potential for reducing stress related symptoms and improving levels of compassion in student midwives.

Links between self-compassion, compassion for others, well-being, compassion fatigue, and burnout have already been explored by Beaumont et al. (2016). In a quantitative survey, Beaumont et al. (2016) examined the relationships between well-being, self-compassion, compassion for others, compassion fatigue and burnout in student midwives ( $n=103$ ). The authors found that just over $50 \%$ of the sample reported scores that were above average for burnout. In addition, participants who reported higher levels of self-judgement also reported lower levels of self-compassion and compassion for others and an increase in symptoms associated with burnout and compassion fatigue. Beaumont et al. (2016) concluded that students wanting a career in midwifery may benefit from learning to be 'kinder to self' when faced with challenging circumstances. To augment these findings, studies by Mollart et al. (2011) found that $60 \%$ of midwives $(n=56)$ reported symptoms of emotional exhaustion that were categorised as moderate to high. Yoshia and Sandall (2013) also found that $50 \%$ of practising midwives reported symptoms of burnout. In response to these findings, this paper will examine the possible benefits of incorporating CMT into student midwives undergraduate education programmes.

\section{Organisational Demands}


The Nursing and Midwifery Council (NMC) recognises the importance of working in environments that foster compassionate care (NMC, 2015). Maben (2010) reported that some nurses felt disillusioned with their role, experienced feelings of frustration, and symptoms of burnout, within just two years from commencing their career. This makes considering an intervention that develops compassion relevant. Bjerknes and Bjork (2010) acknowledge that the working environment can affect all healthcare professionals, with newly qualified nurses sometimes facing organisational obstacles that negatively impact upon their performance. Compassion inhibitors in the working environment include stress and workplace threats that compel individuals to focus on self-defense mechanisms that can lead to judgement errors, and ultimately compassion fatigue (Crawford, 2014; Figley, 1995; 2002). To compound such situations, bureaucratic organisations and staff shortages inhibit capacity of staff to function compassionately (Brown et al, 2013).

Research has also been conducted, which examines the stressors experienced by staff during the processes of delivering bereavement care. Peer support has been found to be one variable that affects the midwives experience of delivering bereavement care (Kirkham, 1999; Mander, 2006). Stress may initially manifest itself in the form of an increase in sickness absence, or through a rise in errors in the workplace. Educators, peers and team leaders must be vigilant to recognise when a student midwife is not coping well with a bereavement situation or an adverse event. Causes of stress or stressors fall into two categories labelled:

(1) External stressors.

(2) Internal stressors.

External stressors 
External stressors consist of physical stimuli within the person's environment, e.g., uncomfortable hot or cold temperatures. Alternatively, the external stimuli may be an abusive colleague or being given too much work to cope with within a given time period.

Internal stressors

Internal stressors consist of stimuli contained within the person's body, e.g., infection, inflammation, lack of sleep, hunger or thirst. Alternatively, the internal stimuli may be psychological in origin, e.g., experiencing worrying thoughts, unpleasant nightmares or anxiety. The working environment is capable of producing both acute and chronic stressors. Other typical causes of stress and trauma at work (Hollins Martin \& Forrest, 2013; Hollins et al., 2016) include:

* Bullying or harassment, by anyone, not necessarily a person's manager.

* $\quad$ Feeling powerless and uninvolved in determining one's own responsibilities.

* Continuous unreasonable performance demands.

* Lack of effective communication and conflict resolution.

* Lack of job security.

* $\quad$ Long working hours.

* Excessive time away from home and family.

* Office politics and conflict among staff.

* A feeling that one's reward is not commensurate with one's responsibility. When a professional recognises signs of stress and trauma in self or a staff member, it is their duty to do something about it. Maternity unit managers, lecturers and supervisors should take responsibility for continuing to provide support to colleagues while they gain experience in all areas of practice. Davies and Coldridge (2015) 
suggest that midwifery educators should consider the variety of acute stress responses that may lead to symptoms of trauma and offer interventions to student midwives which will support them with such challenges. Leary et al., (2007) suggests that self-compassion has been shown to include a healthier reaction to stress. These factors together provide a rationale for creating a more compassionate environment for student midwives on their undergraduate training programmes.

Creating and cultivating environments that foster compassion could help student midwives cope with placement and educational demands (Beaumont, 2016). Gustin and Wagner (2013) found that nurse lecturers who cultivated self-compassion presented with improved compassion for others. This makes the idea of developing self-compassion in student midwives a promising solution for stress reduction and it also has the potential to increase the effectiveness of maternity care provision.

\section{Benefits of self-compassion}

Increasing self-compassion and reducing self-criticism may work towards protecting student midwives from a variety of stress related illnesses, i.e., empathic distress fatigue, burnout and compassion fatigue. For example, Klimecki et al. (2013) demonstrated that compassion training led to a significant improvement in positive emotions when faced with the suffering of others and Neff and Beretvas (2012) found, that individuals who reported high self-compassion scores experienced improved relationships and reported lower levels of self-criticism. Furthermore, Leary et al., (2007) suggests that self-compassion has been shown to include a healthier reaction to stress. Developing an intervention which cultivates compassion could therefore improve students' ability to cope with distress through reducing levels of self-critical judgement and self-attack. 
The act of self-compassion includes reacting to self-suffering with a nonjudgemental attitude, kindness, and understanding (Neff, 2009). Neff (2003) proposes that there are 3 elements of self-compassion: (1) self-kindness, (2) common humanity, and (3) mindfulness. Self-kindness is linked with patience and an understanding of oneself. Common humanity recognises that all human beings make mistakes, and mindfulness aims to take a non-judgemental view when a person experiences negative emotions.

\section{Compassionate Mind Training (CMT) and Compassion Focused Therapy (CFT)}

CMT and CFT were developed by Professor Paul Gilbert to help clinical populations who experienced high levels of self-criticism and shame reduce negative emotional responses. CFT is a term that describes the process and theory of Gilbert's (2009) model, whereas CMT refers to the specific interventions used to trigger the affiliative self-soothing system. The model offers an evolutionary and neuroscientific based approach that explores how the evolution of affiliative emotions regulate threatprocessing and motivational systems (e.g., to help others, improve status, care for family, seek out partners).

\section{Compassion as a flow}

A continuous and external flow of compassion, in the absence of self-compassion, can lead to burnout (Gilbert \& Choden, 2013). Compassion is classified as flowing in 3 ways (Gilbert, 2014):

(1) Compassion for others (compassion flowing out), which involves learning to experience compassion in self, and direct compassion outward towards other people. 
(2) Compassion from others (compassion flowing in), which includes experiencing and accepting compassion from other people.

(3) Self-compassion (self-to-self compassion), which embraces cultivating and developing compassion within ourselves, and directing compassion to the many different parts of self.

Utilising exercises that assist internal and external compassion have shown to be beneficial in clinical populations (Beaumont et al., 2012; Beaumont \& Hollins Martin 2013; 2015; Gilbert \& Proctor, 2005; Mayhew \& Gilbert, 2006), and as such could assemble part of a strategy that attempts to improve compassionate care in student midwives.

\section{$\underline{\text { Rationale for developing Compassionate Mind Training for student midwives }}$}

Placement stressors, trauma, academic demands, staff absences and organisational issues can all take their toll (Chan et al., 2005; McNeely, 2005; Sheen et al., 2014). In place of blaming individuals for their lack of compassionate care, instead, we could offer interventions which are designed to develop greater compassion. Such activities are devised to help build emotional resilience through an individual feeling 'cared for' within organisations. Cultivating self-compassion could help student midwives deal with distress and trauma in the workplace, with CMT using a variety of breathing, postural, and imaginal interventions. During the process, acting techniques (experiencing what it would be like to be a compassionate self), and recall of experiences of giving and receiving compassion are also examined.

\section{Data collection and ethical considerations}

Data will be collected pre and post CMT and its effectiveness will be measured using qualitative and quantitative methods. Qualitative data will be collected via a focus group and quantitative data collected using the Self-Compassion Scale (Neff, 2003), 
Professional Quality of Life Scale (Stamm, 2009), Short Warwick and Edinburgh Mental Well-being Scale (Tennant et al., 2009) and the Compassion For Others Scale (Pommier, 2011). Ethical approval will be sought from the University ethics committee before the sessions are incorporated into the student midwifery curriculum.

\section{CMT IMPLEMENTATION STRATEGY FOR STUDENT MIDWIVES}

Given that CMT has been found useful for helping people experiencing primary trauma, a CMT teaching programme has been designed to explore if it can help student midwives (who bear witness to the trauma of others) develop selfcompassion, build resilience, and reduce self-criticism. The teaching programme devised aims to help student midwives cope with organisational, placement, personal, and academic demands through cultivating compassion (see Figure 1).

Table 1 offers an implementation strategy outlining the interventions that will be added to each year of the midwifery curriculum. Students will also be offered additional support, practice and reflection sessions which they can choose to attend, if they wish to do so. 
Figure 1: Compassionate Mind Training Model for Healthcare Practitioners and Educators (Beaumont, 2016).

\begin{tabular}{|c|c|c|c|}
\hline $\begin{array}{l}\text { Healthcare } \\
\text { practitioner } \\
\text { training } \\
\end{array}$ & $\begin{array}{l}\text { Demands } \\
\text { Academic/ } \\
\text { educational } \\
\text { Patient work } \\
\text { Placement/ } \\
\text { organisational } \\
\text { Personal }\end{array}$ & $\begin{array}{l}\text { Threat System } \\
\text { Activated }\end{array}$ & $\begin{array}{l}\text { As a result, cognitive, behavioural, } \\
\text { emotional and physical symptoms may } \\
\text { be experienced including: Self-criticsim, } \\
\text { shame, blame, guilt, anger, sadness, } \\
\text { headaches, cynicism, depersonalisation, } \\
\text { exhaustion, low energy, feeling } \\
\text { underappreciated/overworked, numb, } \\
\text { disillusioned, overwhelmed, reduced } \\
\text { empathy, loss of meaning and hope, } \\
\text { pre-occupation with anothers trauma, } \\
\text { concentration problems, easily startled, } \\
\text { irritability, difficulty sleeping, intrusive } \\
\text { images, helplessness, irritability, social } \\
\text { withdrawal, diminshed sense of safety, } \\
\text { addictive behaviour, excessive } \\
\text { emotional numbing, lack of self-care }\end{array}$ \\
\hline & $\begin{array}{l}\text { Psycho-education regarding } \\
\text { the warning signs of stress, } \\
\text { fatigue and burnout. } \\
\text { Compassionate Mind Training } \\
\text { (Gilbert, 2009): Introduction } \\
\text { to the theoretical elements of } \\
\text { the model. Exploration of how } \\
\text { our sense of self is created } \\
\text { through an interaction } \\
\text { between our genes, social } \\
\text { experiences and our emotion } \\
\text { regulation systems }\end{array}$ & & $\begin{array}{l}\text { Gilbert's (2009) Compassionate Mind } \\
\text { Interventions include: Mindfulness and } \\
\text { focused attention, soothing rhythm } \\
\text { breathing, compassion focused } \\
\text { imagery, creating a safe place, } \\
\text { compassion as a flow, developing the } \\
\text { compassionate self and ideal } \\
\text { compassionate other, using compassion } \\
\text { to explore and relate to different parts - } \\
\text { multi-self, using compassion to engage } \\
\text { with self-criticism, compassionate letter } \\
\text { writing }\end{array}$ \\
\hline
\end{tabular}
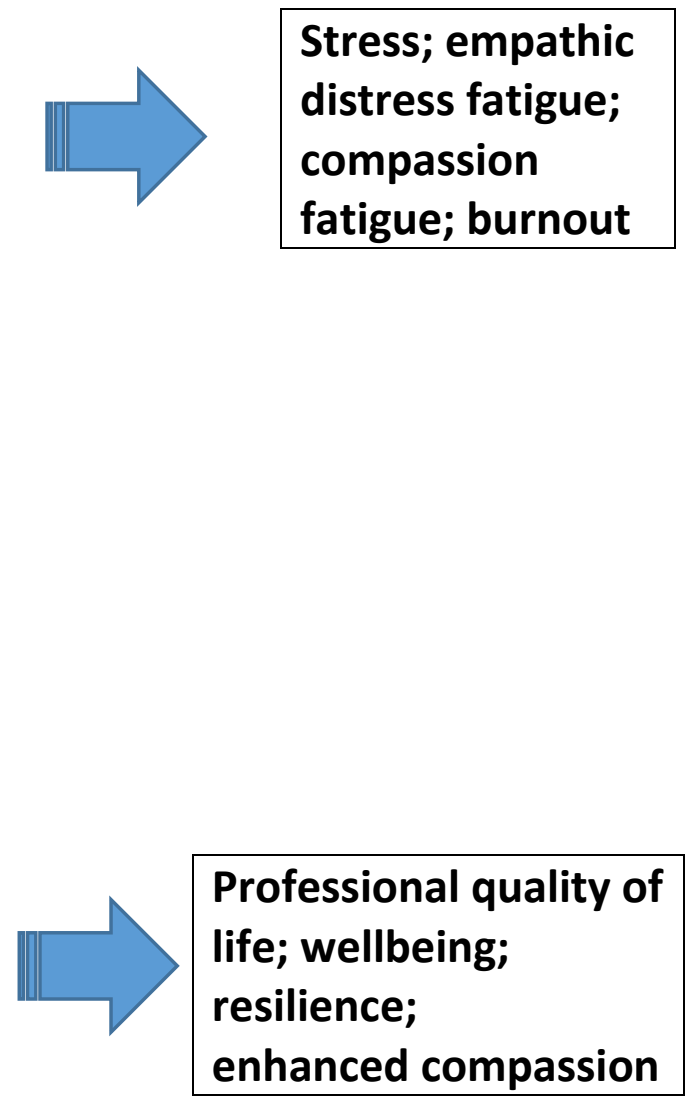

Reprinted with kind permission from Healthcare Counselling and Psychotherapy Journal 
Table 1. Compassionate Mind Training Implementation Strategy

\begin{tabular}{|c|c|}
\hline Session number & Outline of the additions to the curriculum based on Gilbert's $(2009,2014)$ model \\
\hline $\begin{array}{l}\text { 1. Psycho-education: Key } \\
\text { elements of CMT } \\
\text { Introduced in year } 1 \text { of the } \\
\text { curriculum }\end{array}$ & $\begin{array}{l}\text { - A variety of definitions of compassion will be explored } \\
\text { - Student will be introduced to the core theoretical elements of the CMT model } \\
\text { - Student will be introduction to the } 3 \text { circles model (threat, drive and soothing) } \\
\text { - Discussion regarding 'our tricky brain'. E.g., we are all prone to rumination and self-criticism } \\
\text { - Student will be introduced to the two psychologies of compassion }\end{array}$ \\
\hline $\begin{array}{l}\text { 2. Psycho-education \& } \\
\text { developing the } \\
\text { compassionate self } \\
\text { Introduced in year } 1 \text { of the } \\
\text { curriculum }\end{array}$ & $\begin{array}{l}\text { - Discussions regarding self-care and the symptoms associated with stress/burnout/empathic distress } \\
\text { fatigue/compassion fatigue will take place } \\
\text { - Students will be introduced to exercises that aim to develop the compassionate self by recalling } \\
\text { memories of times when they have offered compassion to others and received compassion from } \\
\text { others }\end{array}$ \\
\hline $\begin{array}{l}\text { 3. Formulation: Understanding } \\
\text { yourself } \\
\text { Introduced in year } 2 \text { of the } \\
\text { curriculum }\end{array}$ & $\begin{array}{l}\text { - Discussions regarding how our life history and early experiences shape who we are } \\
\text { - Students will reflect on the potential strategies that they have used to project themselves as a result } \\
\text { of their life experiences } \\
\text { - Exploration regarding the qualities of compassion and an introduction to the fears, barriers and } \\
\text { blocks to compassion }\end{array}$ \\
\hline $\begin{array}{l}\text { 4. Cultivating and building } \\
\text { compassionate capacities } \\
\text { Introduced in year } 2 \text { of the } \\
\text { curriculum }\end{array}$ & $\begin{array}{l}\text { - Students will be introduced to Mindfulness and Focused Attention } \\
\text { - Students will be introduced to Soothing Rhythm Breathing and safe place exercises } \\
\text { - Imagery exercises will be used to stimulate the self-soothing system } \\
\text { - Students will create an ideal compassionate self and compassionate other } \\
\text { - Students will be introduced to exercises which demonstrate the } 3 \text { flows of compassion }\end{array}$ \\
\hline $\begin{array}{l}\text { 5. Building compassionate } \\
\text { capacity using behavioural } \\
\text { practices } \\
\text { Introduced in year } 3 \text { of the } \\
\text { curriculum }\end{array}$ & $\begin{array}{l}\text { - Discussions regarding how we can direct compassion to our 'inner critic' with a focus on behaviour } \\
\text { change and internal dialogue will take place } \\
\text { - Students will be introduced to the concept of method acting - 'experiencing their best compassionate } \\
\text { self' } \\
\text { - Students will practice compassionate assertiveness using role play scenarios } \\
\text { - Experiencing acts of kindness - both for self and others }\end{array}$ \\
\hline
\end{tabular}


Student midwives will initially be introduced to the core theoretical elements of Gilbert's (2009) model. This approach will include exploration of the evolved nature of the human mind, how sense of self is created through an interaction between genetics and social experience, and how shame and self-criticism can impact on levels of compassion. A variety of experiential exercises to cultivate distinctive aspects of compassion will be utilised, that follow a series of defined steps.

\section{Step 1: Psycho-education: key elements of CFT (Gilbert, 2014)}

Students will be introduced to the theoretical components of the compassionate mind model, alongside a critical exploration of how a 'sense of self' is created through:

- An interaction between our genes and social experiences

- Our emotion regulation systems (threat, drive, soothing)

- The nature, origins, and functions of shame and self-critical judgement

- Considering the 'tricky brain' and how "much what goes on in the mind is 'not our fault" (Gilbert, 2014, p.30), because genetically we are programmed for survival. Gilbert (2014) proposes that the brain has the capacity to be intelligent, yet is essentially flawed and therefore vulnerable to a variety of problems that impact on well-being (e.g., fear arousal, rumination, selfcriticism, shame etc.)

The model proposes that humans have 3 systems which regulate emotion (see

Figure 2) (Gilbert, 2009):

- Threat and protection system

- Drive, resource seeking, incentive focused and excitement system

- Affiliative/soothing and safeness system 
Figure 2: Three types of affect regulation system. From Gilbert (2009). The compassionate mind. With kind permission from Constable Robinson.

Drive, excite, vitality

Content, safe, connected

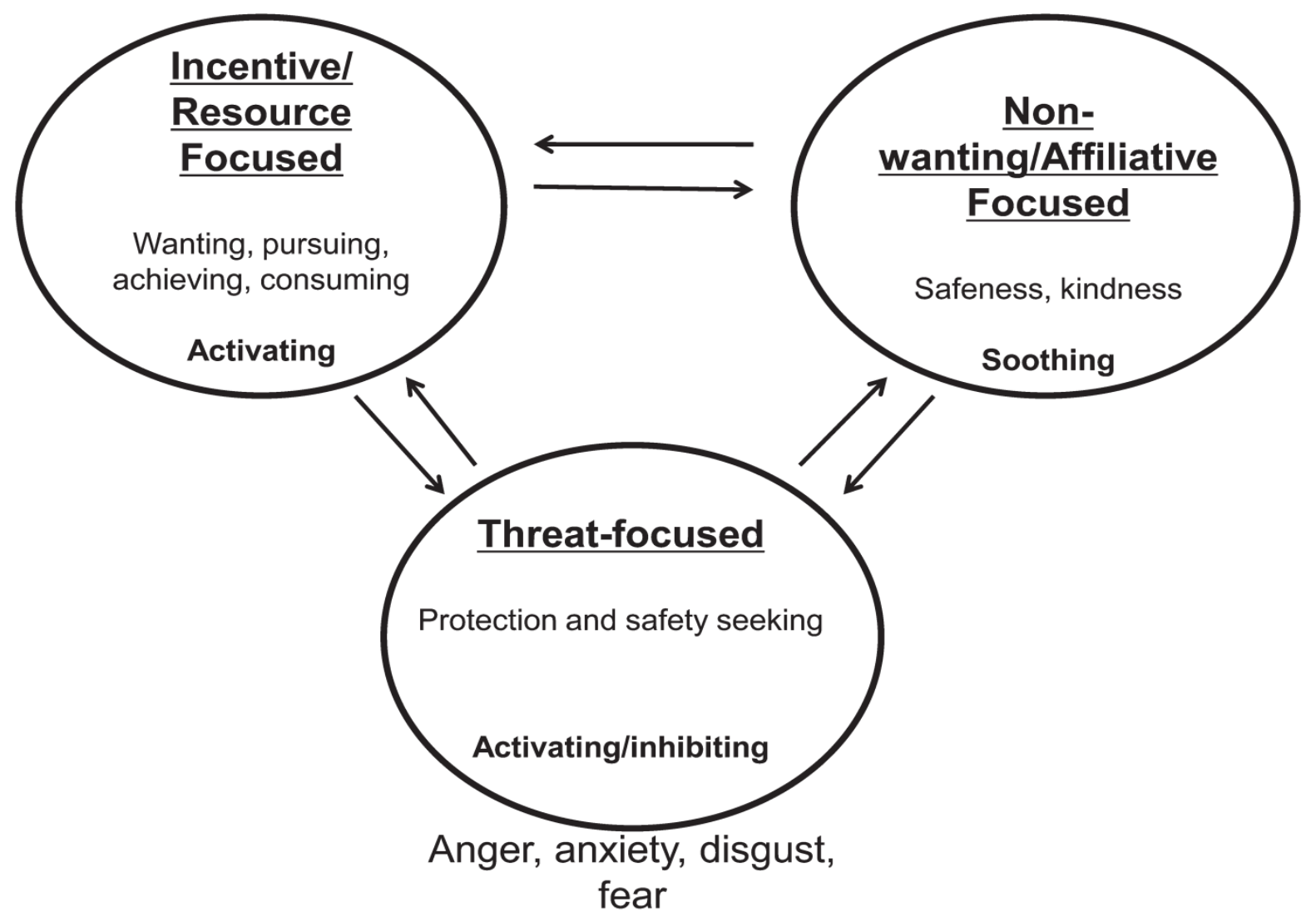

\section{Threat and Protection System (TPS)}

The TPS alerts and directs attention to aspects that an individual perceives as threatening and prompts the body into action. The TPS creates 'better safe than sorry' scenarios that focus on the negative. For example, the person imagines in their mind 'worst case' scenarios and their catastrophic consequences. Self-critical or shame prone individuals are sensitised towards having a dominating threat system (Gilbert, 2009). For example, a midwife engaged in an unexplained stillbirth who blames 'self' for the unfortunate outcome. In turn, this could cause stress to the extent that they imagine being publically shamed and struck off the register.

\section{Drive system}


The drive system evolved to motivate animals to find food and shelter, and seek out sexual partners. The drive system is linked to doing, wanting, achieving, avoiding rejection, and consuming activities (Depue \& Morrone-Strupinsky, 2005). The drive system down-regulates negative emotions from the threat system. That is, when a person engages their drive system (e.g., to win a competition, pass an exam, or gain an award), they experience positive emotions (e.g., excitement, joy, elation) that act as reinforcers for repeating behaviour.

\section{The content, soothing/affiliative system}

The 'soothing/affiliative system' is associated with a number of physiological responses, e.g., physical calming, attachment, caring, and interpersonal connection (Depue \& Morrone-Strupinsky, 2005). The 'soothing/affiliative system' is associated to social connection, affection, and kindness and is responsible for reducing threat responses to feared stimuli and for activating feelings of safety, bonding and trust. In distressing events, being in receipt of compassion generates security within the group. Hence, activities that engage the 'soothing /affiliative system', increase selfcompassion, feelings of safeness, and help to regulate the 'affect regulating system' in response to threat (e.g., self-criticism).

In a nutshell, the aim of CMT is to balance the 3 systems, build the soothing affiliative system, and understand how the 3 systems impact upon one another. Cultivating a compassionate mind involves being prepared to change, having wisdom about how to take effective action (Gilbert, 2014), and having a caring motivation to develop a variety of key attributes and skills linked to compassion (see Table 2). Gilbert (2009) refers to the first psychology of compassion, which involves:

- An awareness and noticing of suffering 
- Turning towards suffering

- Having an ability to tolerate and engage with distress, as opposed to avoiding, denying or dissociating from suffering

The second psychology of compassion includes:

- Acknowledging, knowing, and finding out what to do when suffering is experienced (Germer \& Siegel, 2012; Gilbert, 2014).

The 2 psychologies of compassion are action focused and include a desire to acquire skills that attempt to alleviate suffering. For example, skills training involves the person learning to direct attention, behave, reason, and respond to feelings and sensations with compassion.

Table 2: The key attributes and skills of compassion (Gilbert, 2009).

\begin{tabular}{|l|l|}
\hline $\begin{array}{l}\text { The first psychology of compassion } \\
\text { (Compassionate Attributes) }\end{array}$ & $\begin{array}{l}\text { The second psychology of compassion } \\
\text { (Compassionate Skills) }\end{array}$ \\
\hline $\begin{array}{l}\text { Care for well-being: Developing a caring } \\
\text { motivation to notice and turn toward } \\
\text { suffering with a wish to alleviate distress }\end{array}$ & $\begin{array}{l}\text { Attention: Learning how to notice that } \\
\text { our attention can be directed by us } \\
\text { (what we focus on expands). This is } \\
\text { linked to mindfulness, being in the } \\
\text { present moment without judging or }\end{array}$ \\
$\begin{array}{l}\text { Sensitivity to distress: Learning to } \\
\text { recognise and be attentive to one's own } \\
\text { and other people's distress }\end{array}$ & $\begin{array}{l}\text { riticising } \\
\text { Reasoning: Learning to reason in ways }\end{array}$ \\
$\begin{array}{l}\text { Sympathy: The ability to be emotionally } \\
\text { moved by feelings of distress rather } \\
\text { than feeling dissociated from it }\end{array}$ & $\begin{array}{l}\text { that are helpful (exploration of cognitive } \\
\text { processes with a focus on 'what will be } \\
\text { genuinely helpful right now') }\end{array}$ \\
$\begin{array}{l}\text { Distress tolerance: Using the } \\
\text { compassionate mind to tolerate difficult } \\
\text { emotions by moving toward suffering } \\
\text { rather than avoiding suffering }\end{array}$ & $\begin{array}{l}\text { Behaviour: Behaving in ways that are } \\
\text { helpful (facing fears, reducing safety } \\
\text { behaviours, acts of gratitude, } \\
\text { compassionate letter writing, doing } \\
\text { helpful things for self or others) }\end{array}$ \\
$\begin{array}{l}\text { Empathy: Seeing the world through the } \\
\text { eyes of another and understanding our } \\
\text { own emotions which, can involve taking } \\
\text { the perspective of our different parts } \\
\text { (our angry self, our sad self, our } \\
\text { compassionate self, our critical self) }\end{array}$ & $\begin{array}{l}\text { Sensory: Using breathing practices, } \\
\text { vocal tones, facial and body postures to } \\
\text { generate physical states, which are } \\
\text { conducive to affect regulation and } \\
\text { compassion }\end{array}$ \\
\hline
\end{tabular}


Non-judgement: The process involves acceptance and non-judgement. Individuals are taught techniques that aim to help them become more aware of and let go of self-attacking and selfcriticism
Feeling: Learning to pay attention to, and compassionately respond to the different emotions we feel

Imagery: Using imagery and meditation exercises to stimulate the soothing systems

\section{Step 2: Compassion in midwifery}

The education provided in Step 1 will be strengthened by discussions regarding symptoms of empathic distress fatigue, compassion fatigue, (secondary trauma/vicarious trauma), burnout, and occupational stress, all of which impact upon the performance of midwifery staff. Discussions will include examination of how trauma experiences (e.g., traumatic childbirth, stillbirth, lack of support) in the workplace impact on well-being. Students' beliefs surrounding compassionate thinking, and compassionate behaviour (e.g., what constitutes self-compassion verses self-critical behaviour and thinking) will be explored and a critical appraisal of helpful and unhelpful behaviours in the workplace, in terms of scenarios examined. Students will discuss stress coping strategies and role-play exercises will be used to help equip students with the necessary tools to face workplace stressors. Students will recall memories of giving and receiving compassion.

\section{Step 3: Formulation (Gilbert, 2009; 2014)}

The reflections in Step 2 will then be reinforced through learning about early life experiences and how to create coping strategies to self-soothe, drive forward, and defend against threat. Self-awareness will be bolstered through exploring interactions students have with 'self'. For example, what tone of voice is used when a mistake is made, what fears are learnt in childhood, and what helpful and unhelpful 
strategies are used to regulate emotions and interactions with others. Fears, blocks and barriers to compassion will be examined.

Step 4: Cultivating and building compassionate capacities (Gilbert, 2009; 2014)

Participators will be introduced to a variety of interventions. For example, breathing and imagery techniques that create safeness and calm. Exercises designed to help student midwives experience 'Compassion as a Flow' will be introduced. In addition, Mindfulness and Focused Attention would be taught to direct attention towards being in the present moment without judgement or criticism. Breathing exercises that include Soothing Rhythm Breathing (SRB), which moderates heart rate variability and is linked to positive health outcomes will be incorporated into training. SRB engages the soothing-affiliative system and produces feelings of calm. Creating a Safe Place using guided imagery interventions would be included to help student midwives create a sense of safety and calm. In addition, Compassion Focused Imagery exercises will be taught which stimulate the soothing system. Participators will create in their mind, or through art, an image of their Ideal Compassionate Other. The image created requires that the person uses a compassionate, non-judgmental approach.

Step 5: Building compassionate capacity using behavioural practices (Gilbert, 2009) The compassionate qualities cultivated in Step 4 will be used to challenge unhelpful behaviours and self-critical thoughts. For example, a student midwife criticising his/her ability to cope when a childbearing woman experiences an adversity, such as an infant abnormality.

Utilising skills cultivated in these steps will be used to explore helpful alternative assertive behaviours. Student midwives will also be introduced to creative ways of 
developing self-compassion, through use of acting and art to depict the 'bully within' and the 'compassionate self'.

Step 6: Using the compassionate mind to engage with difficulties (Gilbert, 2009)

Participators will use their compassionate mind to engage with self-criticism, organisational pressures, and trauma memories. Discussions about sad, angry, or anxious parts, which respond simultaneously within a situation will take place. For example, a student midwife may simultaneously experience sadness about leaving university, anxiety about commencing a new role, and perhaps joy at successfully completing the course. In contrast, participators will also explore how to engage with compassion to help self-criticism, which involves employing the compassionate part of self and directing compassionate attributes (e.g., empathy, distress tolerance, non-judgement) to self-critical parts.

\section{CONCLUSION}

Whilst many students face similar challenges, student midwives face a set of distinctive emotional challenges that can test their confidence knowledge and capacity. Student midwives work with people who at times experience high levels of distress. Being part of these traumatic experiences, if not well managed, can propagate emotional fallout. In this instance, we are talking about experiencing symptomology of secondary traumatic stress and burnout. Given that healthcare educators levels of self-compassion improved, and self-critical judgement reduced, post CMT training (Beaumont et al., 2016), and because CMT has proven effective in treating symptoms of trauma in clinical populations (Beaumont et al., 2012;

Beaumont \& Hollins Martin, 2013; 2015), it has shown potential to benefit midwives who bear witness to trauma. As such, we recommend that CMT be incorporated into a midwifery undergraduate degree programme, and its effectiveness measured. In 
the current climate, it is timely and appropriate for midwifery educators to explore concepts of compassion in greater depth. 


\section{References}

Beaumont, E., 2016. Building resilience by cultivating compassion. Healthcare Counselling and Psychotherapy Journal. 16 (3), 22-27.

Beaumont, E., Galpin, A., Jenkins, P., 2012. Being kinder to myself: A prospective comparative study, exploring post-trauma therapy outcome measures, for two groups of clients, receiving either Cognitive Behaviour Therapy or Cognitive Behaviour Therapy and Compassionate Mind Training. Counselling Psychology Review. 27 (1), 31-43.

Beaumont, E., Hollins Martin, C.J., 2013. Using compassionate mind training as a resource in EMDR: A case study. Journal of EMDR Practice and Research.7(4), 186-199.

Beaumont, E., Hollins Martin, C.J., 2015.A narrative review exploring the effectiveness of Compassion-Focused Therapy. Counselling Psychology Review. 30(1), 21-32.

Beaumont, E., Durkin, M., Hollins Martin, C.J., Carson, J., 2016. Compassion for others, self-compassion, quality of life and mental well-being measures and their association with compassion fatigue and burnout in student midwives: A quantitative survey. Midwifery. 34, 239-244.

Bjerknes, M.S., Bjørk, I.T., 2012. Entry into nursing: an ethnographic study of newly qualified nurses taking on the nursing role in a hospital setting. Nursing Research and Practice 690348. doi: 10.1155/2012/690348.

Breines, J.G., Chen, S., 2012. Self-Compassion Increases Self-Improvement Motivation.Personality Social Psychology DOI:

http://doi.org/10.1177/0146167212445599

Brown, B., Crawford, P., Gilbert, P., Gilbert, J., Gale, C., 2013. Practical compassions: repertoires of practice and compassion talk in acute mental healthcare. Sociology of Health \& IIIness ISSN 0141-9889pp. 1-17 doi: 10.1111/1467-9566.12065

Chang E.M., Hancock, K.M., Johnson, A., Daly, J., Jackson, D., 2005. Role stress in nurses: review of related factors and strategies for moving forward. Nursing \& Health Sciences. 7(1), 57-65.

Crawford, P., Brown, B., Kvangarsnes, M., Gilbert, P., 2014.The design of compassionate care. Journal of Clinical Nursing. 23(23-24), 3589-99.

Cummins, J., Bennett, V., 2012. Compassion in Practice, Nursing, Midwifery and Care Staff. Our Vision and Strategy. Department of Health Commissioning Board. https://www.england.nhs.uk/nursingvision/compassion/[8/1/2016]. 
Davies, S., Coldridge, E., 2015. 'No Man's Land': An exploration of the traumatic experiences of student midwives in practice. Midwifery http://dx.doi.org/10.1016/j.midw.2015.05.001

Depue R, A., Morrone-Strupinsky J, V., 2005. A neurobehavioral model of affiliative bonding. Behavioral and Brain Sciences. 28, 313-95.

Figley, C.R., 1995. Compassion fatigue as secondary traumatic stress disorder: An overview. Compassion fatigue: coping with secondary traumatic stress disorder in those who treat the traumatized. New York: Brunner/Maze.

Figley, C.R., 2002. Treating compassion fatigue. New York: Brunner/Mazel.

Gilbert, P., 2005. Social mentalities: A biopsychosocial and evolutionary reflection on social relationships. In M. Baldwin (Ed.), Interpersonal cognition (pp. 299333). New York, NY: Guilford.

Gilbert. P., 2009. The Compassionate Mind. London: Constable.

Gilbert, P., 2014. The origins and nature of compassion focused therapy. BritishJournal of Clinical Psychology. 53(1), 6-41.

Gilbert, P., Choden., 2013. Mindful compassion. Robinson: London.

Gilbert, P.,Procter, S., 2006. Compassionate mind training for people with high shame and self-criticism: Overview and pilot study of a group therapy approach. Clinical Psychology \& Psychotherapy. 13, 353-379.

Gustin, L. W.,Wagner, L., 2013.The butterfly effect of caring-clinical nursing teachers' understanding of self-compassion as a source to compassionate care. Scandinavian Journal of Caring Sciences, 27(1), 175-183.

Hollins Martin, C.J., Forrest, E., 2013. Bereavement care for childbearing women and their families: an interactive workbook. Routledge, Abingdon, Oxon (UK).

Hollins Martin, C.J., Forrest, E., Wylie, L., Martin, C.R., 2013. The Understanding Bereavement Evaluation Tool (UBET) for midwives: factor structure and clinical research applications. Nurse Education Today 33: 1153-1159.

Hollins Martin C.J., Forrest, E., Wylie, L., Martin, C.R., 2014. An evaluative survey to assess the effectiveness of using an interactive workbook to deliver bereavement education to undergraduate student midwives. Midwifery 30, 942-948.

Hollins Martin, C.J., Robb, Y., Forrest, E., 2016. An exploratory qualitative analysis of student midwives views of teaching methods that could build their confidence to deliver perinatal bereavement care. Nurse Education Today. 39 (2016) 99-103. http://dx.doi.org/10.1016/j.nedt.2015.12.023

Joinson, C., 1992. “Coping with compassion fatigue.” Nursing 22, 116-21. 
Kirkham, M., 1999. The culture of midwifery in the National Health Service in England. Journal of Advanced Nursing. 30(3): 732-739.

Klimecki, O., Singer, T., 2012. "Empathic distress fatigue rather than compassion fatigue? Integrating findings from empathy research in psychology and social neuroscience." In Pathological Altruism. Edited by Barbara Oakley, Ariel Knafo, Guruprasad Madhavan and David Sloan Wilson. New York: Oxford University Press, pp. 368-83.

Klimecki, O. M., Leibergh, S., Lamm, C., Singer, T., 2013. Functional neural plasticity and associated changes in positive affect after compassion training. Cerebal Cortex. 23(7), 1552-1561.

Leary, M.R., Tate, E.B., Adams, C.E., Allen, A.B., Hancock, J., 2007. Selfcompassion and reactions to unpleasant self-relevant Events: The implications of treating oneself kindly. Journal of Personality and Social Psychology, 92, 887-904.

Leinweber, J., Rowe, H., 2010. The costs of 'being with the woman': secondary traumatic stress in midwifery. Midwifery 26, 76-87.

McNeely, E., 2005. The consequences of job stress for nurses' health: time for a check-up. Nursing Outlook. 53(6): 291-299.

Maben, J., Cornwell, J., Sweeney, K., 2010. In praise of compassion, Journal of Research in Nursing, 15, 1, 9-13.

Mander, R., 2006. Loss and Bereavement in Childbearing (2nd ed.). Routledge: London.

Mayhew S., Gilbert P., 2008. Compassionate mind training with people who hear malevolent voices. A case series report. Clinical Psychology and Psychotherapy. 15, 113-38.

Miller, K.I., Stiff, J.B., Ellis, B.H., 1988. Communication and empathy as precursors to burnout among human service workers. Communication Monographs 55, 250-265.

Mollart. L., Skinner, V.M., Newing, C., Foureur, M., 2013. Factors that may influence midwives work-related stress. Women and Birth. 26, 26-32.

Neff, K.D., 2003.The development and validation of a scale to measure selfcompassion. Self and Identity. 2, 223-250.

Neff, K.D., Beretvas, S. N., 2013. The role of self-compassion in romantic relationships. Self and ldentity. 12(1), 78-98. 
Nursing and Midwifery Council, 2015. The Code. Professional standards of practice and behaviour for nurses and midwives. Available at: http://www.nmc$\underline{\text { uk.org/code }}$

Pommier, E.A., 2011. The compassion scale: dissertation abstracts international (Section A). Humanities and Social Sciences. 72, 1174.

Raab, K., 2014. Mindfulness, self-compassion, and empathy among health care professionals: a review of the literature. Journal of Health Care Chaplaincy 20 (3), 95-108.

Richards, K., 2013. Self-care is a lifelong journey. Nurs. Econ. 31. (4), 198-202.

Sabo, B.M., 2006. Compassion fatigue and nursing work. Can we accurately capture the consequences of caring work? International journal Nursing Practice 12, 136-142.

Shanafelt, T.D., Bradley, K.A., Wipf, J.E., Back, A.L., 2002. Burnout and selfreported patient care in an internal medicine residence program. Family Journal. 12, 396-400.

Sheen, K., Slade, P., Spiby, H., 2014. An integrative review of the impact of indirect trauma exposure in health professionals and potential issues of salience for midwives. J.Adv.Nurs.70, 729-743.

Spickard, A. Gabbe, S.G., Christensen, J.F., 2002. Mid-career burnout in generalist and specialist physicians. Journal of the American Medical Association. 288, 1447-1450.

Stamm, B.H., 2009. Professional Quality of Life: Compassion Satisfaction and Fatigue Version 5 (ProQOL). /www.isu.edu/ bhstamm or www.proqol.org.

Tennant, R., Hiller, L., Fishwick, R., Platt, S., Joseph, S., Weich, S., Parkinson, J., Secker, J., Stewart-Brown, S., 2009. The Warwick and Edinburgh Mental Well-Being Scale (WEMWBS): Development and UK Validation. Health and Quality of Life Outcomes. 5(63), 1-13.

Vahey, D.C., Aiken, L.H., Sloane, D.M., Clarke, S.P., Vargas, D., 2004. Nurse burnout and patient satisfaction. Medical Care. 42, 57-66.

van Mol, M.M., Kompanje, E.J., Benoit, D.D., Bakker, J., Nijkamp, M.D., 2015. The Prevalence of Compassion Fatigue and Burnout among Healthcare Professionals in Intensive Care Units: A Systematic Review. PloS one, 10(8), p.e0136955.

Yoshida, Y., Sandall, J., 2013. Occupational burnout and work factors in community and hospital midwives: a survey analysis. Midwifery. 29 (8), 921-6. 
